\title{
A Low-Energy lon Scattering (LEIS) Study of the Influence of the Vanadium Concentration on the Activity of Vanadium-Niobium Oxide Catalysts for the Oxidative Dehydrogenation of Propane
}

\author{
R. H. H. Smits, ${ }^{*}$ K. Seshan, ${ }^{*}$ J. R. H. Ross* ${ }^{*}, 1$ L. C. A. van den Oetelaar, $†$ J. H. J. M. Helwegen, $\dagger$ \\ M. R. Anantharaman, $\dagger^{2}$ and H. H. Brongersma $\dagger$ \\ *Faculty of Chemical Technology, University of Twente, P.O. Box 217, 7500 AE Enschede, The Netherlands; and \\ $\dagger$ Faculty of Physics and Schuit Institute of Catalysis, Eindhoven University of Technology, P.O. Box 513, \\ $5600 \mathrm{MB}$ Eindhoven, The Netherlands
}

Received December 27, 1994; revised July 20, 1995

\begin{abstract}
A series of vanadium-niobium oxide catalysts in which the vanadia content varies between 0.3 and $18 \mathrm{~mol} \%$ was prepared by coprecipitation. These catalysts were characterized by X-ray diffraction (XRD), X-ray photoelectron spectroscopy (XPS), low-energy ion scattering (LEIS), and by catalytic testing in the oxidative dehydrogenation reaction of propane. The results of the surface analysis by XPS and LEIS are compared. It is concluded that the active site on the catalyst surface contains $2.0 \pm 0.3$ vanadium atoms on average. This can be understood by assuming the existence of two or three different sites: isolated vanadium atoms, pairs of vanadium atoms, or ensembles of three vanadium atoms. At higher vanadium concentration more vanadium clusters with a higher activity are at the surface. LEIS revealed that as the vanadium concentration in the catalyst increases, vanadium replaces niobium at the surface. At vanadium concentrations above $8 \mathrm{~mol} \%$, new phases such as $\beta$ - $(\mathrm{Nb}$, $\mathrm{V}_{2} \mathrm{O}_{5}$ which are less active because vanadium is present in isolated sites are formed, while the vanadium surface concentration shows a slight decrease. 1995 Acadenic Press, Inc.
\end{abstract}

\section{INTRODUCTION}

There is currently an increasing interest in the catalytic activation of lower alkanes. Following the initial work of Chaar et al. (1) on the oxidative dehydrogenation of $n$ butane, a number of papers on the oxidative dehydrogenation of propane and butane have appeared (2-6). Propane is usually investigated because the oxidative dehydrogenation of this molecule may be an attractive alternative route compared to conventional dehydrogenation and cracking for the production of propylene. Oxidative dehydrogena-

\footnotetext{
${ }^{1}$ Present address: University of Limerick, Plassey Technological Park, Limerick, Ireland.

${ }^{2}$ Present address: Department of Physics, Cochin University of Science and Technology, Cochin, India.
}

tion of isobutane is another interesting application as the isobutylene produced could be used in the synthesis of methyl tertiary-butyl ether (MTBE). Research on vanadium-magnesium oxide catalysts has focused on discussions on the nature of the active phase: magnesium orthovanadate or pyrovanadate $(1,3,4)$. In a recent paper (5), Kung and Kung claimed that both orthovanadate and pyrovanadate are selective for oxidative dehydrogenation of propane but only magnesium orthovanadate is selective in the oxidative dehydrogenation of butane. Contamination with potassium caused by the preparation method used by Siew Hew Sam et al. (4) resulted in a less selective catalyst.

We have attempted to improve the vanadiummagnesium oxide catalyst system by doping it with various elements $(6,7)$, but these attempts were not successful. We have, therefore, focused our attention on niobium pentoxide for the following reasons:

- Niobium is in the same group of the periodic table as vanadium and is expected to have similar properties.

- Niobium is much more difficult to reduce than vanadium (easy reduction often causes low selectivity in selective oxidation reactions).

- It had been previously shown, for example, that the addition of niobium oxide to a mixture of molybdenum and vanadium oxides improves the activity and selectivity of this system for oxidative dehydrogenation reactions $(8-10)$

We have shown in previous papers $(11,12)$ that high selectivities toward propylene were possible using pure niobia, but that the conversions were low.

We have recently presented the results of experiments that show that the activity of niobia can be improved considerably, while maintaining high selectivity, by adding other suitable elements such as vanadium, chromium, and molybdenum (13). Vanadium appeared to be the most 
beneficial. In the same publication, some results obtained with vanadium-containing catalysts prepared by different methods were presented. In two articles $(14,15)$, the results of a more detailed and systematic investigation of the influence of preparation methods on the performance of vanadium-niobium oxide catalysts were shown. It was concluded that the method of addition of vanadium to niobium oxide has a large influence on the performance of the resulting catalyst. A preparation method such as coprecipitation should be selected because it gives a homogeneous distribution of vanadium in the catalyst. The differences between the catalysts prepared by the various preparation methods become smaller upon use. This might be caused by a redistribution of the vanadium under the reducing conditions in which the catalyst was tested.

For a better understanding of the catalytic activity of catalysts, surface science techniques such as $\mathrm{X}$-ray photoelectron spectroscopy (XPS) and low-energy ion scattering (LEIS) can indicate the surface composition and structure of catalysts. While XPS probes several monolayers deep and reveals information about the composition and chemical state of atoms in these surface layers, LEIS probes only the outermost atomic layer of the surface of a catalyst. It was shown by Jacobs et al. (16) and Eberhardt et al. (17) that LEIS can be applied successfully to study the composition (quantitatively) and structure of the outermost layer of a supported vanadia catalyst.

This article gives the results of an investigation of the influence of the amount of vanadium added to the catalyst on its catalytic activity with the aim of finding an optimum amount of vanadium. The results of the LEIS experiments shed some more light on the way in which the vanadium is incorporated into the surface structure of the catalyst. This is expected to help in identifying the nature of the active sites for the oxidative dehydrogenation of propane.

\section{EXPERIMENTAL}

\section{Catalyst Preparation}

A series of catalysts with vanadium concentrations in the range $0.25-20 \mathrm{~mol} \%$ was prepared by coprecipitation as described below. These samples are assigned with a code $\mathrm{V}_{x} \mathrm{Nb}$, where $x=\operatorname{mol} \%$ vanadium oxide in niobia. A solution of $40 \mathrm{~g}$ oxalic acid dihydrate, $10 \mathrm{~g}$ of hydrated niobia (Niobium Products Company, Inc., $80 \mathrm{wt} \%$ niobium oxide), and an appropriate amount of ammonium metavanadate in $250 \mathrm{ml}$ water was first prepared (Solution A). A buffer solution was also prepared by adding concentrated ammonia to a saturated solution of $5 \mathrm{~g}$ of oxalic acid in water (approx. $100 \mathrm{ml}$ ) until the $\mathrm{pH}$ reached 9 (Solution B). A drop of freshly precipitated hydrated niobia suspension was added to this buffer solution to prevent oversaturation and the resulting $\mathrm{pH}$ fluctuations. The $\mathrm{pH}$ was monitored by a $\mathrm{pH}$ electrode and was maintained automatically during the preparation procedure by adding concentrated ammonia. Solution $\mathrm{A}$ and an $8 \%$ ammonia solution were added simultaneously in a flow ratio of $2: 1$ to the buffer Solution $\mathrm{B}$ of $\mathrm{pH} 9$ at $30^{\circ} \mathrm{C}$. Solution $\mathrm{A}$ was added in a flow rate of $10-15 \mathrm{ml} / \mathrm{min}$. The resulting suspension was filtered on two layers of fine filter paper (Whatman No. 50 ) and washed twice with cold water. It was observed in the preparation of the samples $\mathrm{V} 10 \mathrm{Nb}, \mathrm{V} 15 \mathrm{Nb}$, and $\mathrm{V} 20 \mathrm{Nb}$ that the filtrate had a blue color, indicating the presence of dissolved vanadium oxalate. All the products were dried at $120^{\circ} \mathrm{C}$ overnight and calcined in air for $5 \mathrm{~h}$ at $630^{\circ} \mathrm{C}$.

As a reference for the LEIS measurements, samples of $\beta-(\mathrm{Nb}, \mathrm{V})_{2} \mathrm{O}_{5}$ [which is known to contain approximately $10 \mathrm{~mol} \%$ vanadium oxide (18)] were prepared by heating samples of V10Nb in air for $15 \mathrm{~h}$ at $700,800,900,1000$, and $1100^{\circ} \mathrm{C}$. The samples calcined at 1000 and $1100^{\circ} \mathrm{C}$ were found by XRD to be monophasic $\beta-(\mathrm{Nb}, \mathrm{V})_{2} \mathrm{O}_{5}$.

\section{Characterization of the Catalysts}

The catalysts were characterized by catalytic testing, BET surface area measurement, $\mathrm{X}$-ray fluorescence (XRF), X-ray photoelectron spectroscopy, X-ray diffraction (XRD), and low-energy ion scattering. In addition, some of the precursors of the catalysts were investigated by thermogravimetric analysis in combination with differential scanning calorimetry (TGA/DSC).

The catalysts ( $600 \mathrm{mg}, 0.3$ - to 0.6 -mm grains) were tested for catalytic activity using a flow reaction system that has been described previously (12). The gas feed consisted of $9.6 \mathrm{vol} \%$ oxygen, $29.4 \mathrm{vol} \%$ propane, and balance $\mathrm{He}$, with a total flow of $136 \mathrm{~cm}^{3} / \mathrm{min}$. In each test the sample was heated in a series of eight steps of $20-30^{\circ} \mathrm{C}$ in the required temperature range, and a sequence of analyses was made during each temperature step; each temperature was maintained for $2 \mathrm{~h}$. The temperature range for testing was selected in such a way that more than $20 \%$ oxygen conversion (usually $100 \%$ ) was reached at the highest temperature and that the reaction rate at $425^{\circ} \mathrm{C}$ could be determined. The $\mathrm{V} 0.25 \mathrm{Nb}$ catalyst was thus tested in the range $380-580^{\circ} \mathrm{C}$, while the V7.5 Nb catalyst was tested at $320-460^{\circ} \mathrm{C}$.

Surface area determination was carried out according to the BET method using a Micromeretics ASAP 2400 system with nitrogen as adsorbent.

A Kratos XSAM 800 system was used for XPS measurements using $\mathrm{Mg} K \alpha$ radiation. The vanadium surface concentration was determined by measuring the peak areas of Nb3d and V2p and using sensitivity factors reported for the Kratos system ( 2.4 for $\mathrm{Nb} 3 d, 1.95$ for $\mathrm{V} 2 p$ ). The $\mathrm{V} 2 p$ peak area was taken as 1.5 times the $\mathrm{V} 2 p^{3 / 2}$ peak area after automatic subtraction of the O1s satellite peak (521 $\mathrm{eV}$ ) falling between the $\mathrm{V} 2 p^{1 / 2}$ and $\mathrm{V} 2 p^{3 / 2}$ peaks (522 and $519 \mathrm{eV}$ ). Since the sensitivity of the equipment varied between different series of measurements, the results of each 
set of measurements was corrected by repeating the measurement of a number of reference samples from the previous series of measurements.

A Philips PW 1710 diffractometer was used to obtain $\mathrm{X}$-ray powder diffraction patterns using $\mathrm{Cu} K \alpha$ radiation.

Combined TGA/DSC patterns were recorded on a Polymer Laboratories STA 625 system using a flow of air or nitrogen and a heating rate of $10^{\circ} \mathrm{C} / \mathrm{min}$.

The low-energy ion scattering experiments were carried out using the NODUS equipment. The essentials of this equipment have been described in detail elsewhere (19) and only a brief description is given here. ${ }^{4} \mathrm{He}^{+}$ions having $3 \mathrm{keV}$ kinetic energy are produced using a Leybold ion source (type IQE 12/38). A Wien filter is applied to mass filter the ion beam. The ion beam then hits the sample at a $90^{\circ}$ angle with respect to the sample surface (spot size approximately $7 \mathrm{~mm}^{2}$ ). Those ions scattered over an angle of $142^{\circ}$ are analyzed by a modified cylindrical mirror analyzer. The kinetic energy of the backscattered ions is determined by changing the potential on the deflection plates of this analyzer. The ions are detected by a ring detector containing a set of eight channeltrons. The system is normally kept at a pressure of $10^{-9} \mathrm{mbar}$, which increases to $10^{-8}$ mbar (mostly helium) when the ion beam and the ring-shaped flood gun are on. Charging of the sample is minimized by pressing the powder into a lead sample holder (ensuring that no lead appears at the surface) and by flooding the surface of the sample from all sides with low-energy electrons (approximately $10 \mathrm{eV}$ ) from a ringshaped filament. Samples are normally pretreated with 20 mbar oxygen at $240^{\circ} \mathrm{C}$ in a pretreatment chamber attached to the vacuum chamber to remove contaminants such as carbon, but this was found to have no effect since the LEIS signals were similar with and without pretreatment. This pretreatment was therefore omitted for these samples. An ion beam current of $26 \mathrm{nA}$ was used. Several scans were taken and each scan takes $45 \mathrm{~s}$. It was estimated that the time needed to remove one monolayer was at least $3000 \mathrm{~s}$. The first scan was not used because it was found to deviate from the subsequent scans (possibly due to shielding effects of hydroxyl groups present at the surface); after the tenth scan, the effects of preferential sputtering of oxygen became apparent. Thus, scans $2-10$, which show stable signals, were added and analyzed by integration of the peak areas after background subtraction, illustrated in a typical LEIS spectrum of the V3Nb catalyst shown in Fig. 1. A linear background (drawn between two fixed final energies) is used because the shape of the baseline is not well known. Each sample was analyzed two to four times and peak areas were averaged, using a fresh sample each time. The $\mathrm{V} 5 \mathrm{Nb}$ and $\mathrm{V} 10 \mathrm{Nb}$ catalysts were also measured after catalytic testing. The LEIS signals of these used catalysts were similar to the fresh catalysts. This is further confirmed by the stable behavior of the catalysts during catalytic

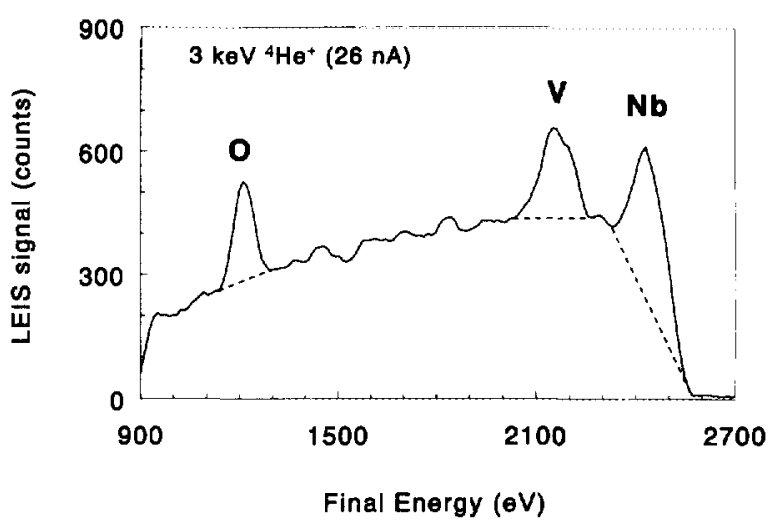

FIG. 1. Typical LEIS spectrum of a V-Nb oxide catalyst (V3Nb, 3 mol\% V). The peak areas (above the dashed background lines) are used to quantify the outermost surface composition.

measurements. Therefore we assume that the surface composition determined for the fresh catalysts reflects the surface composition under reaction conditions, which makes it possible to consider a correlation between catalytic activity and surface composition of these catalysts. The vanadium surface concentration was calculated using a LEIS sensitivity ratio $\mathrm{V} / \mathrm{Nb}$ of 0.63 . This sensitivity ratio was determined from the ratio of the peak areas obtained when measuring the pure metals, taking into account the molar areas of the metals. This calibration method has been applied successfully to quantify the surface concentration of binary alloys of $\mathrm{V}-\mathrm{Nb}(20), \mathrm{Nb}-\mathrm{Ta}(21)$, and $\mathrm{Cu}-\mathrm{Pd}(22)$.

\section{RESULTS AND DISCUSSION}

The results obtained from the characterization of the series of catalysts prepared by coprecipitation are shown in Tables 1 and 2.

\section{Bulk Properties}

The XRF results of Table 1 show that with vanadium concentrations lower than $7 \mathrm{~mol} \%$, the samples contain slightly more vanadium than intended. This is caused by the fact that the hydrated niobia used contained somewhat more water than reported by the supplier ( $20 \mathrm{wt} \%$ ), thus offsetting the estimation of the amount of niobia used. It can be concluded that with up to $7 \mathrm{~mol} \%$ vanadia, the selected coprecipitation method results in a quantitative precipitation of the vanadium. At vanadium concentrations higher than $7 \mathrm{~mol} \%$, the precipitation was no longer quantitative. The vanadium concentrations found were lower than intended, but continued to increase with increasing vanadium concentration in the solution, indicating that the maximum amount of vanadium that can be precipitated by this method was not yet reached. It should be noted here that vanadium by itself is soluble in ammonia 
TABLE 1

Results of the Characterization of the V-Nb Oxide Catalysts by XRF, XPS, LEIS, BET Surface Area Determination, XRD, and Catalytic Testing

\begin{tabular}{|c|c|c|c|c|c|c|c|c|}
\hline \multirow[b]{3}{*}{ Sample } & \multicolumn{3}{|c|}{ Concentration V (mol\%) } & \multirow{3}{*}{$\begin{array}{c}\text { BET area } \\
\left(\mathrm{m}^{2} / \mathrm{g}\right)\end{array}$} & \multirow{3}{*}{$\begin{array}{l}\text { XRD phases } \\
\text { present }^{a}\end{array}$} & \multirow{3}{*}{$\underset{\left(\mu \mathrm{mol} / \mathrm{m}^{2} / \mathrm{s}\right)^{b}}{\text { Rate }}$} & \multirow[b]{3}{*}{ Selectivity } & \multirow{3}{*}{$\begin{array}{c}\text { Temp. } \\
\left({ }^{\circ} \mathrm{C}\right)\end{array}$} \\
\hline & \multirow{2}{*}{$\begin{array}{l}\text { Bulk } \\
\text { XRF }\end{array}$} & \multicolumn{2}{|c|}{ Surface } & & & & & \\
\hline & & XPS & LEIS & & & & & \\
\hline $\mathrm{V} 0.25 \mathrm{Nb}$ & 0.29 & 2.1 & 0 & 7.8 & $\mathrm{TT}$ & 0.018 & 91 & 552 \\
\hline $\mathrm{V} 0.5 \mathrm{Nb}$ & 0.60 & 5.0 & 10 & 7.7 & $T$ & 0.045 & 91 & 503 \\
\hline $\mathrm{V} 0.75 \mathrm{Nb}$ & 0.91 & 6.3 & 22 & 8.2 & TT & 0.079 & 89 & 470 \\
\hline $\mathrm{V} 1 \mathrm{Nb}$ & 1.1 & 8.6 & 23 & 7.6 & $T$ & 0.130 & 86 & 445 \\
\hline $\mathrm{V} 1.5 \mathrm{Nb}$ & 1.6 & 10 & 34 & 7.3 & $T$ & 0.214 & 83 & 419 \\
\hline $\mathrm{V} 2 \mathrm{Nb}$ & 2.2 & 14 & 38 & 6.8 & $T$ & 0.294 & 80 & 398 \\
\hline V3Nb & 3.2 & 15 & 44 & 7.4 & $T$ & 0.377 & $79^{t}$ & 383 \\
\hline V5Nb & 5.2 & 18 & 50 & 6.8 & $\mathrm{~T}$ & 0.665 & 77 & 370 \\
\hline V7.5Nb & 7.1 & 21 & 56 & 8.2 & $T, \operatorname{tr} \beta$ & 0.675 & $75^{\circ}$ & 361 \\
\hline V10Nb & 9.1 & 22 & 49 & 7.2 & T, $\beta$ & 0.330 & 82 & 390 \\
\hline V15Nb & 13.2 & 24 & 51 & 7.7 & $\beta, T$ & 0.389 & 82 & 384 \\
\hline $\mathrm{V} 20 \mathrm{Nb}$ & 17.7 & 25 & 52 & 9.9 & $\mathrm{U}, \operatorname{tr} \mathrm{V}$ & 0.201 & 83 & 403 \\
\hline
\end{tabular}

${ }^{a}$ TT, TT-niobia; T, T-niobia; $\beta, \beta$ - $(\mathrm{Nb}, \mathrm{V})_{2} \mathrm{O}_{5} ; \mathrm{U}$, unknown phase; $\mathrm{V}, \mathrm{V}_{2} \mathrm{O}_{5} ;$ tr, trace.

${ }^{b}$ Of propane consumption at $425^{\circ} \mathrm{C}$.

'To propene at $10 \%$ oxygen conversion, at the temperature given in the next column.

${ }^{d} 82 \%$ at $415^{\circ} \mathrm{C}$.

$83 \%$ at $428^{\circ} \mathrm{C}$.

in the form of ammonium vanadate. It is thus remarkable that vanadium can be precipitated quantitatively here because of the presence of niobium in the solution. It is not clear whether the vanadium is removed from the solution by adsorption on the niobium precipitate or by the formation of a mixed vanadium-niobium precipitate.

The TGA/DSC results shown in Table 2 indicate that most of the oxalate remaining in the dried precipitate is lost between 200 and $300^{\circ} \mathrm{C}$. The DSC signal shows an endothermic peak immediately followed by an exothermic peak, which is typical for decomposition of oxalate to car-

\section{TABLE 2}

Results of the Characterization of Selected Catalyst Precursors by TGA/DSC Experiments

\begin{tabular}{lcccccc}
\hline Sample & $\begin{array}{c}\text { Temp. } \\
\left({ }^{\circ} \mathrm{C}\right)^{a}\end{array}$ & $\begin{array}{c}\text { Weight } \\
\text { loss }(\%)^{b}\end{array}$ & $\begin{array}{c}\text { Temp. } \\
\left({ }^{\circ} \mathrm{C}\right)^{c}\end{array}$ & $\begin{array}{c}\text { Weight } \\
\text { gain }(\%)^{b}\end{array}$ & $\begin{array}{c}\text { Temp. } \\
\left({ }^{\circ} \mathrm{C}\right)^{c}\end{array}$ & $\begin{array}{c}\text { Weight } \\
\text { loss }(\%)^{a}\end{array}$ \\
\hline V0.5Nb & 259 & 26 & 540 & 1.0 & 582 & 3.1 \\
V3Nb & 259 & 26 & 509 & 1.2 & 587 & 3.8 \\
V7.5Nb & 258 & 16 & 482 & 1.0 & 591 & 3.8 \\
V15Nb & 257 & 21 & 457 & 0.9 & 594 & 4.4 \\
\hline
\end{tabular}

${ }^{a}$ Of weight derivate peak.

${ }^{b}$ Relative to final weight.

' Of DSC peak. bon monoxide and carbon dioxide and subsequent oxidation of the carbon monoxide to give carbon dioxide. The weight loss is not as large as that for the niobium oxalate supplied by Niobium Products Company, Inc. (80\%), which means that either most of the oxalate had disappeared during the drying step, or the precipitate formed initially was not a stoichiometric oxalate, but an oxalate-hydroxide. The latter is more probable, since little weight was lost during drying. An exothermic DSC peak and a corresponding weight gain in the TGA curve are observed for all the samples in the temperature range of $400-550^{\circ} \mathrm{C}$. When the V3Nb sample was heated in a similar way in a nitrogen atmosphere, this was not observed. The position of the DSC peak was strongly dependent on the amount of vanadium. The amount of weight gain was, however, independent of the vanadium content. It is known that vanadium is reduced by the oxalic acid in solution to form $\mathrm{V}^{4+}$ oxalate complexes, which are blue in color. Niobium also forms oxalate complexes in an oxalic acid solution (9), but it is generally assumed to be present in its oxidized $\mathrm{Nb}^{5+}$ form. The most probable explanation of the weight gain observed is that a vanadium-catalyzed oxidation of niobium (and possibly of vanadium) takes place here, since the vanadium decreased the temperature needed for the oxidation and the weight gain was too large to be explained by oxidation of $\mathrm{V}^{4+}$ to $\mathrm{V}^{5+}$ alone. This means that the niobium was reduced somewhere during the process of preparation of 
TABLE 3

Results of the Characterization of the New Phase in the V20Nb Catalyst by XRD

\begin{tabular}{cccc}
\hline $\begin{array}{c}d \text { spacing } \\
(\AA)\end{array}$ & $\begin{array}{c}\text { Intensity } \\
(\%)\end{array}$ & $\begin{array}{c}d \text { spacing } \\
(\AA)\end{array}$ & $\begin{array}{c}\text { Intensity } \\
(\%)\end{array}$ \\
\hline 3.97 & 100 & 1.87 & 15 \\
3.43 & $25^{a}$ & 1.77 & 10 \\
3.11 & 10 & 1.75 & $20^{a}$ \\
3.01 & 50 & 1.72 & 10 \\
2.95 & 20 & 1.69 & 10 \\
2.80 & $20^{\prime \prime}$ & 1.66 & 15 \\
2.60 & $15^{a}$ & 1.62 & 10 \\
2.40 & 25 & 1.60 & 15 \\
1.99 & 35 & 1.31 & 10 \\
1.97 & 10 & & \\
\hline
\end{tabular}

"Also occurs in $\mathrm{V}_{2} \mathrm{O}_{5}$.

the samples. This phenomenon was not observed in any catalyst precursor prepared by other methods, nor in the decomposition of niobium oxalate. The last DSC peak (Table 2, last column) can be attributed to the crystallization of amorphous niobia into the TT-phase. The associated weight loss was normally not observed when heating hydrated niobia, but only when heating niobium oxalate. The weight loss may be attributed to residual carbon-containing species being excluded from amorphous niobia when it crystallizes. The phase transformation was delayed more when more vanadium was present in the sample, indicating that the vanadium was well dispersed in the bulk of the sample.

The BET areas found (Table 1) appear to be independent of the amount of vanadium added. Only in the samples containing $7 \mathrm{~mol} \%$ vanadium or more were mixed oxides of vanadium and niobium observed by XRD (Table 1). The samples $\mathrm{V} 10 \mathrm{Nb}$ and $\mathrm{V} 15 \mathrm{Nb}$ contain $\beta-(\mathrm{Nb}, \mathrm{V})_{2} \mathrm{O}_{5}$, which was described by Goldschmidt (18) as having a structure similar to H-niobia. Wadsley and Andersson (23) suggested that in this phase, vanadium replaces the niobium present in isolated tetrahedral sites at the junctions of blocks of $\mathrm{NbO}_{6}$ octahedra. An unknown phase that has not been reported previously in the literature was found in sample V20 Nb along with some vanadium oxide. The intensities and $d$ spacings of the lines of this phase are shown in Table 3. In the samples containing less than $7 \mathrm{~mol} \%$ vanadium, only TT-niobia and T-niobia were found. No measurable change in lattice parameters indicating the formation of a solid solution was observed. However, this does not exclude the formation of a solid solution, since the change in lattice parameters may be too small to be observed. It is not possible to quantify the amount of the various phases present accurately from XRD analysis.

\section{Catalytic Testing}

Figure 2 shows the rate of propane consumption at $425^{\circ} \mathrm{C}$ as a function of the amount of vanadium in the catalyst. It appears that the activity of the catalysts increases approximately linearly until $5 \mathrm{~mol} \%$ vanadium. The activity of the V7.5 $\mathrm{Nb}$ sample was only slightly higher than that of $\mathrm{V} 5 \mathrm{Nb}$. This deviation from linearity coincides with the formation of a small amount of $\beta-(\mathrm{Nb}, \mathrm{V})_{2} \mathrm{O}_{5}$ (Table 1). In samples $\mathrm{V} 10 \mathrm{Nb}$ and $\mathrm{V} 15 \mathrm{Nb}$, this was the major phase, and these samples were much less active than samples $\mathrm{V} 5 \mathrm{Nb}$ and $\mathrm{V} 7.5 \mathrm{Nb}$. It thus appears that $\beta-(\mathrm{Nb}, \mathrm{V})_{2} \mathrm{O}_{5}$ was much less active than the vanadium-containing $\mathrm{T}$-niobia phase. The sample V20Nb had a very low activity, and it may hence be assumed that the unknown phase in this material was also not very active.

The selectivities observed are shown in Table 1. When the selectivity to propene at $10 \%$ oxygen conversion is compared at a temperature of approximately $420^{\circ} \mathrm{C}$ (see footnotes $d$ and $e$ of Table 1 and data for sample $\mathrm{V} 1.5 \mathrm{Nb}$ ), the selectivity appears to be independent of the vanadium concentration (24). Any variation in selectivity visible in Table 1 is contributed to the difference in experimental conditions under which they are measured.

Temperature-programmed reduction of the $\mathrm{V}-\mathrm{Nb}$ oxide catalysts were carried out to identify the changes in reducibility from $\mathrm{Nb}-\mathrm{O}-\mathrm{Nb}$ bonds (in pure $\mathrm{Nb}_{2} \mathrm{O}_{5}$ ) to $\mathrm{Nb}-\mathrm{O}-\mathrm{V}$ (in catalysts with low $\mathrm{V}$ content), to $\mathrm{V}-\mathrm{O}-\mathrm{V}$ (in catalysts with high $V$ content). The results are presented elsewhere $(6,25)$. It was seen that incorporation of $\mathrm{V}$ improves the ease of reduction of $\mathrm{Nb}_{2} \mathrm{O}_{5}$. However, no clear conclusions could be made (from peak positions and intensities) regarding structural changes around $\mathrm{V}$ atoms.

\section{Surface Properties}

The results of the analysis of the surface composition by XPS and LEIS are given in Table 1 and are also shown

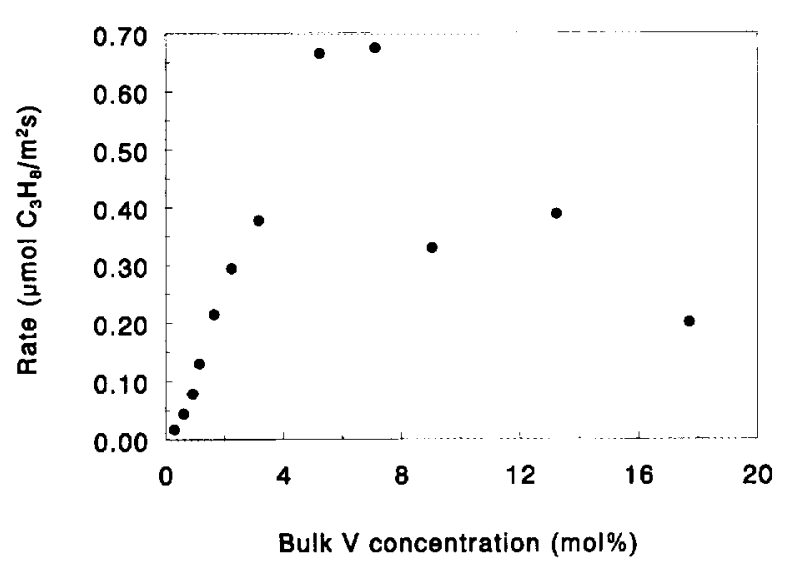

FIG. 2. Rate of propane consumption at $425^{\circ} \mathrm{C}$ versus the bulk concentration of vanadium in the catalysts. 


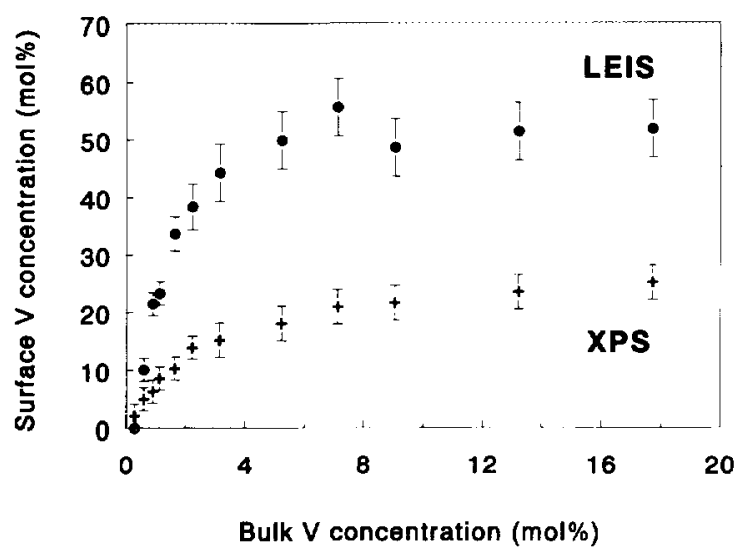

FIG. 3. Surface concentration of vanadium as determined by XPS and LEIS versus the bulk vanadium concentration.

in Fig. 3, which gives the surface concentration, determined by XPS and LEIS, as a function of the vanadium content of the catalysts. XPS shows that the surface concentration of vanadium initially increases strongly with increasing bulk concentration of vanadium, but that the surface concentrations level off at a bulk concentration of $4 \mathrm{~mol} \%$. The same can be seen with LEIS, except that at the highest vanadium bulk concentrations, the surface concentration decreases slightly. When these results are compared with the results of activity measurements displayed in Fig. 2, it can be concluded that the catalytically active surface sites consist of vanadium and that the significantly lower activities of the samples $\mathrm{V} 10 \mathrm{Nb}, \mathrm{V} 15 \mathrm{Nb}$, and $\mathrm{V} 20 \mathrm{Nb}$ (compared to those with a lower bulk concentration of vanadium) cannot be completely explained by the slightly lower concentration of vanadium at the outer surface as shown by LEIS. That the catalytically active species consist of vanadium is also supported by the turnover frequency (TOF) measurements (24). The TOF for propane conversion is $0.03 \mathrm{~s}^{-1}$ for a $2 \mathrm{~mol} \%$ vanadia on niobia catalyst, whereas the TOF is $0.0003 \mathrm{~s}^{-1}$ for pure niobia.

Since the probing depth of XPS is much deeper (approximately $50 \AA$ for vanadium), it gives an average vanadium concentration over several monolayers. The vanadium concentrations revealed by LEIS are about a factor of 2-3 higher than revealed by XPS. This reflects a surface enrichment of vanadium in these catalysts.

The results of the LEIS analysis of the sample $\mathrm{V} 10 \mathrm{Nb}$ calcined at temperatures up to $1100^{\circ} \mathrm{C}$ are shown in Fig. 4. This figure shows that the concentration of vanadium at the surface of the material decreases as the calcination temperature is increased. Results of XRD analysis showed that the amount of $\beta-(\mathrm{Nb}, \mathrm{V})_{2} \mathrm{O}_{5}$ increased as the calcination temperature was increased, until monophasic $\beta-(\mathrm{Nb}$, $\mathrm{V})_{2} \mathrm{O}_{5}$ was formed at $1000^{\circ} \mathrm{C}$. These results thus seem to confirm that the slightly lower concentration of vanadium

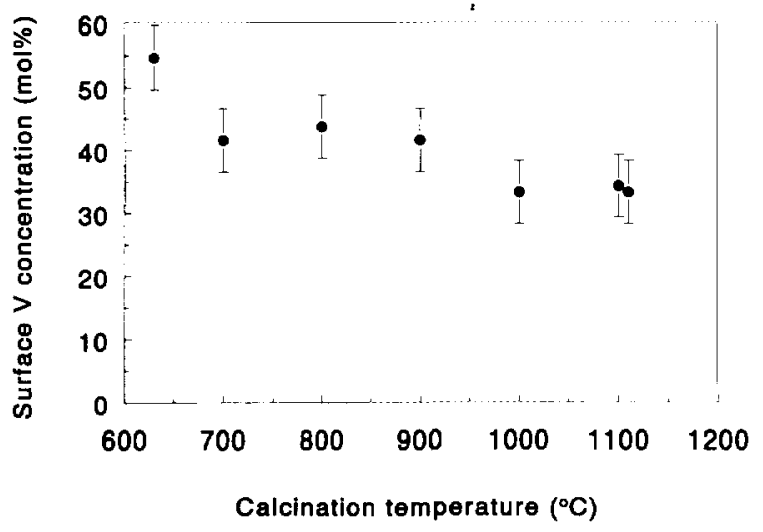

FIG. 4. Surface concentration of vanadium in the V10Nb catalyst as determined by LEIS versus the calcination temperature. Calcination at $1100^{\circ} \mathrm{C}$ was carried out twice for 19 and $24 \mathrm{~h}$, respectively. To distinguish both treatments in the figure, the latter is displayed at $1110^{\circ} \mathrm{C}$.

found at the surface of the catalysts $\mathrm{V} 10 \mathrm{Nb}$ and $\mathrm{V} 15 \mathrm{Nb}$ is indeed caused by the formation of the phase $\beta-(\mathrm{Nb}, \mathrm{V})_{2} \mathrm{O}_{5}$ in these catalysts, which also appear to have less activity according to Fig. 2. A small but constant amount of potassium was also detected here.

Since LEIS is only sensitive to the first atomic layer of the surface of a catalyst, interesting conclusions can be drawn when studying the absolute intensities arising from the various elements at the surface (Fig. 5). The intensity of the vanadium signal increases as a function of the vanadium content of the catalyst, while the niobium signal decreases. The oxygen signal, however, remains more or less constant. It is illustrated in Fig. 5 by the straight line of the added $\mathrm{V}$ and $\mathrm{Nb}$ signal (after correction for differences in sensitivity) that the $\mathrm{V}$ and $\mathrm{Nb}$ signals are mirror images of each other. This indicates that niobium is replaced by vanadium at the surface when the bulk vanadium concentration is increased. Further, vanadium occupies the sites

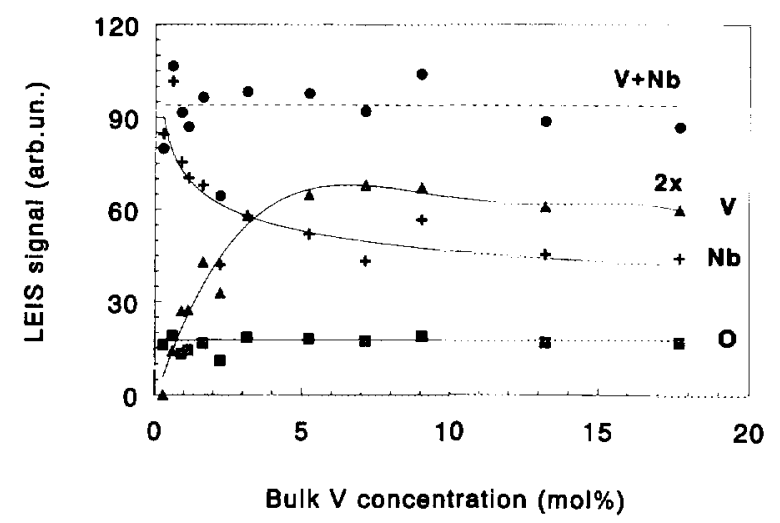

FIG. 5. Absolute LEIS signals as a function of the bulk vanadium concentration. The added $\mathrm{V}+\mathrm{Nh}$ signals are corrected for differences in sensitivity (sensitivity ratio of $\mathrm{V} / \mathrm{Nb}$ is 0.63 ). 


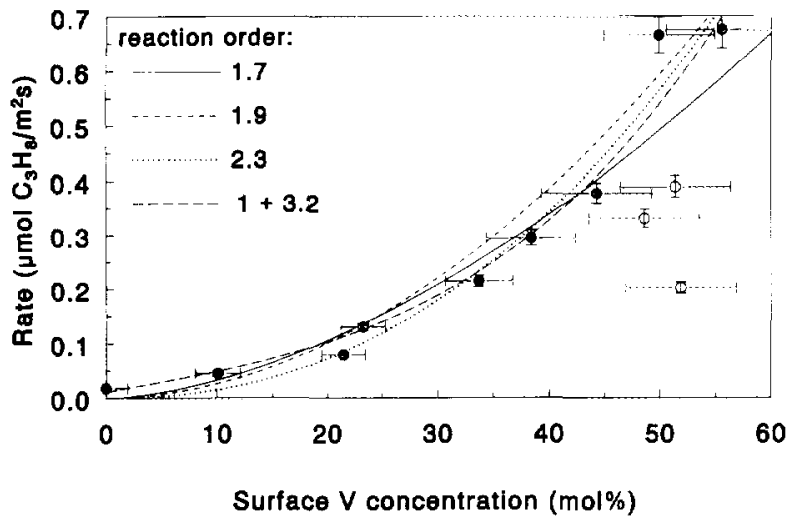

FIG. 6. Rate of propane consumption versus the surface vanadium concentration as determined by LEIS. The open markers are data from the $\mathrm{V} 10 \mathrm{Nb}, \mathrm{V} 15 \mathrm{Nb}$, and $\mathrm{V} 20 \mathrm{Nb}$ catalysts and are not used in the fits. Different curves are plotted to get information about the active site(s) of the $\mathrm{V}-\mathrm{Nb}$ oxide catalyst (see text).

that are normally occupied by niobium in the T-niobia phase without changing the oxygen structure resulting in a constant oxygen signal. Evidence that this is indeed the case was found using ${ }^{51} \mathrm{~V}$ solid-state NMR (26).

\section{The Active Site}

Surface analysis techniques can be used to get more information about the active site by plotting the rates of propane consumption against the surface concentration of vanadium; Fig. 6 shows the specific reaction rate as a function of surface concentration as determined by LEIS. Similar results were obtained when the XPS data were used. The data points (excluding those corresponding to the samples V10Nb, V15Nb, and V20Nb; open markers in Fig. 6) were fitted with a power function to find the order of reaction with respect to the number of vanadium atoms at the surface. For both methods of surface analysis, an average reaction order of $2.0 \pm 0.3$ was found to fit the data. It is difficult to determine the exact dependence of the rate on the vanadium concentration (see fits in Fig. 6). A linear regression technique results in a reaction order of 1.7-1.9 (depending if absolute or relative errors are minimized); a nonlinear regression technique (LevenbergMarquardt algorithm) results in a reaction order of 2.3 . The data can also be fitted (within experimental error) using a combination of reaction order 1 and 3.2 in vanadium surface concentration. So it should be clear from Fig. 6 , taking the error bars into account, that the exact reaction order cannot be determined here.

However, it is evident that these results indicate the existence of two or three different active sites at the surface of the catalysts: isolated vanadium atoms, pairs of vanadium atoms, or ensembles of three vanadium atoms. The isolated vanadium sites are less active than the vanadium clusters. The minimum activity of isolated $\mathrm{V}$ sites was found for the catalysts with concentrations $\leq 0.75$ bulk mol\% V. The V10Nb and V15Nb catalysts partly contain $\beta$ - $(\mathrm{Nb}, \mathrm{V})_{2} \mathrm{O}_{5}$ with isolated $\mathrm{V}$ atoms and therefore the activity is partly reduced in comparison with the $V 7.5 \mathrm{Nb}$ catalyst, where $V$ clusters dominate the activity.

The idea that clusters of $\mathrm{V}$ atoms are more active can also be seen in Fig. 7, where the intrinsic activity per site is plotted against the vanadium surface concentration. There is an increase in activity per site with surface concentration even though the increase is not very large.

It was shown by Owen et al. (3) that for the oxidative dehydrogenation of propane the selectivity to propene was inversely proportional to the reduction potential of the cation for a number of orthovanadates. Owen et al. did not report the specific activities of their materials; however, since the selectivity of an active site is usually inversely proportional to its activity, it can be assumed that the activity of an orthovanadate is proportional to the reduction potential of the cation neighboring the isolated vanadium site occurring in an orthovanadate. It is thus reasonable to suppose that ensembles of vanadium atoms are more active than isolated vanadium atoms, since a bridging oxygen atom between two easily reducible vanadium atoms is more active than an oxygen atom between a vanadium atom and a (less easily reducible) niobium atom. In a study by Desponds et al. (10) on the oxidative dehydrogenation of ethane over $\mathrm{Mo}-\mathrm{V}-\mathrm{Nb}$ oxide catalysts it was found that the presence of $\mathrm{Nb}$ is important in the selectivity of these catalysts since it inhibits the total oxidation of ethane to carbon dioxide.

It also appears that the catalysts containing more than $7 \mathrm{~mol} \%$ vanadia are not less active because they have a significantly lower surface concentration of vanadium, but mainly because the isolated vanadium sites occurring in the $\beta-(\mathrm{Nb}, \mathrm{V})_{2} \mathrm{O}_{5}$ phase that is formed are less active.

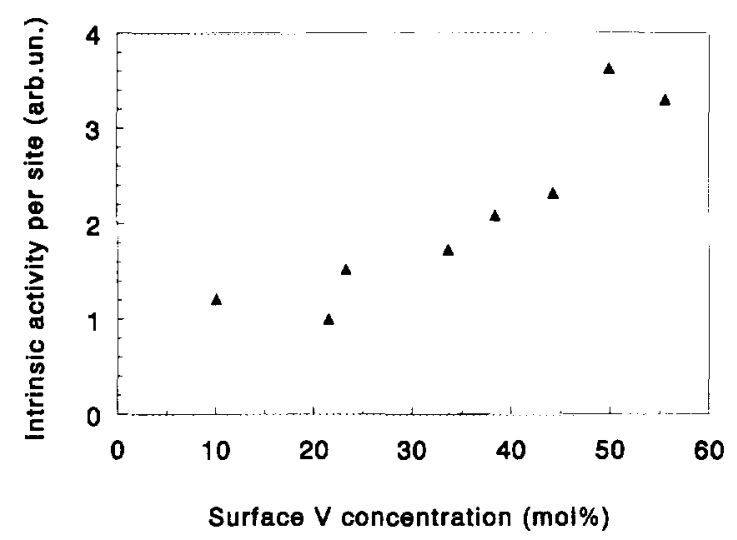

FIG. 7. The intrinsic activity per site as a function of the surface vanadium concentration determined by LEIS. The intrinsic activity per site is determined by dividing the propane consumption rate by the surface vanadium concentration and is normalized to 1 for the lowest activity. 


\section{CONCLUSIONS}

The results presented in this paper show that a preparation method to make homogeneous samples by coprecipitation yields catalysts that are highly active. At vanadium concentrations below approximately $7.5 \mathrm{~mol} \%$, the active phase has a structure that is indistinguishable by XRD from $T$-niobia. When increasing the amount of vanadium in this phase, LEIS measurements indicates that vanadium replaces niobium at the surface of the catalyst.

LEIS can also quantify the vanadium surface concentration of the outermost atomic layer. The LEIS measurements show a vanadium surface concentration that is approximately two to three times higher than that from XPS measurements due to the difference in probing depth. The increase in specific activity as a function of surface vanadium concentration can be described by a power function with exponent $2.0 \pm 0.3$. This can be explained by assuming that the activity of the catalyst is caused by the combined activity of less active isolated vanadium sites and more active vanadium clusters at the surface. As the vanadium concentration is increased, less active isolated vanadium sites may be replaced by more active ones that contain two neighboring vanadium atoms. As the vanadium concentration is increased further, even more active ensembles of three or more vanadium atoms may be formed. The latter explains the increase in reaction order with respect to vanadium atoms at the surface. The reaction order depends on which species dominate the activity at a particular vanadium surface concentration.

If the vanadium concentration is increased to above 7.5 mol\% vanadia, mixed oxide phases that are less active than the catalysts in which only T-niobia was found are formed. This is caused partially by the fact that these catalysts contain slightly less vanadium in the first atomic layer at the surface, but mainly by the fact that they contain less active isolated vanadium sites.

From these conclusions, a model for the structure of the active site can be derived. If vanadium is occupying some of the sites of T-niobia normally occupied by niobium, the vanadium will be coordinated by six, seven, or nine oxygen ions. The changes in activity per vanadium atom at the surface may be explained by assuming that the initial isolated vanadium sites are replaced by other sites as the vanadium concentration increases. These sites are different from the initial sites by the number of vanadium ions relative to niobium ions in the second coordination sphere around the vanadium atom. They are more active because the oxygen in the first coordination sphere is more active as it is flanked by two easily reducible vanadium ions rather than a vanadium ion and a niobium ion. The mixed oxides are less active as these oxides contain vanadium in isolated tetrahedral sites.

\section{ACKNOWLEDGMENTS}

The investigations were supported in part by the Technology Foundation (STW) and the Netherlands' Foundation of Chemical Research (SON) with financial aid from the Netherlands' Organisation of the Advancement of Scientific Research (NWO). M. R. Anantharaman thanks the Department of Science \& Technology (DST) of the Government of India for financial support.

\section{REFERENCES}

1. Chaar, M. A., Patel, D., Kung, M. C., and Kung, H. H., J. Catal. 105, 483 (1987).

2. Smits, R. H. H., Seshan, K., and Ross, J. R. H., in "Proceedings, DGMK Conference on Selective Hydrogenations and Dehydrogenations, Kassel, Germany" (M. Baerns and J. Weitkamp, Eds.), p. $211,1993$.

3. Owen, O. S., Kung, M. C., and Kung, H. H., Catal. Lett. 12, 45 (1992).

4. Siew Hew Sam, D., Soenen, V., and Volta, J. C., J. Catal. 123, 417 (1990).

5. Kung, M. C., and Kung, H. H., J. Catal. 134, 668 (1992).

6. Seshan, K., Swaan, H. M., Smits, R. H. H., van Ommen, J. G., and Ross, J. R. H., Stud. Surf. Sc. Catal. 55, 505 (1990).

7. Smits, R. H. H., Seshan, K., van Ommen, J. G., and Ross, J. R. H., unpublished results.

8. Oda, Y., Uchida, K., Suhara, M., and Morimoto, T., UK Patent $1,377,325$ (1974).

9. Thorsteinson, E. M., Wilson, T. P., Young, F. G., and Kasai, P. H., J. Catal. 52, 116 (1978).

10. Desponds, O., Keiski, R. L., and Somorjai, G. A., Catal. Lett. 19. 17 (1993).

11. Smits, R. H. H., Seshan, K., and Ross, J. R. H., J. Chem. Soc., Chem. Commun. 8, 558 (1991).

12. Smits, R. H. H., Seshan, K., and Ross, J. R. H., Stud. Surf. Sci. Catal. 72, 221 (1992)

13. Smits, R. H. H., Seshan, K., and Ross, J. R. H., in "Catalytic Selective Oxidation" (S. T. Oyama and J. W. Hightower, Eds.), ACS Symposium Series No. 523, p. 380. Am. Chem. Soc., Washington. DC, 1992

14. Smits, R. H. H., Seshan, K., Leemreize, H., and Ross, J. R. H., Catal. Today 16, 513 (1993).

15. Smits, R. H. H., de Vries, Y. A., Seshan, K., and Ross, J. R. H., Catal. Today, in press.

16. Jacobs, J.-P., van Leerdam, G. C., and Brongersma, H. H., in "Fundamental Aspects of Heterogeneous Catalysis Studied by Particle Beams" (H. H. Brongersma and R. A. van Santen, Eds.). NATOASI Series B 265, p. 399. Plenum, New York, 1991.

17. Eberhardt, M. A., Houalla, M., and Hercules, D. M., Surf. Interface Anal. 20, 766 (1993).

18. Goldschmidt, H. J., Metallurgia 62, 211 (1960)

19. Brongersma, H. H., Hazewindus, N., van Nieuwland, J. M., Otten, A. M. M., and Smets, A. J., Rev. Sci. Instrum. 49, 707 (1978)

20. Martin, P. J., Loxton, C. M., Garrett, R. F., MacDonald, R. J., and Hofer, W. O., Nucl. Instrum. Methods 191, 275 (1981).

21. van den Oetelaar, L. C. A., Jacobs, J.-P., Mietus, M. J., Brongersma, H. H., Semenov, V. N., and Glebovsky, V. G., Appl. Surf. Sci. 70/ 71, 79 (1993).

22. Ackermans, P. A. J., Krutzen, G. C. R., and Brongersma, H. H., Nucl. Instrum. Methods B 45, 384 (1990).

23. Wadsley, A. D., and Andersson, S., in "Perspectives in Structural Chemistry" (J. D. Dunitz and J. A. Ibers, Eds.), Vol. 3, p. 19. Wiley, New York, 1970

24. Watling, T. C., Deo, G., Seshan, K., Wachs, I. E., and Lercher, J. A., Catal. Today, in press.

25. Smits, R. H. H., Ph.D. thesis, University of Twente, 1994.

26. Smits, R. H. H., Seshan, K., Ross, J. R. H., and Kentgens, A. P. M. J. Phys. Chem. 99, 9169 (1995). 